\title{
Why cigarette advertising should be banned
}

\author{
To stop children from becoming addicted to cigarettes
}

Health ministers of the European Community are due to vote next week on the community's draft directive to ban cigarette advertising. Each year smoking kills some 431000 people in the community, ${ }^{1} 110000$ of them in Britain. ${ }^{2}$ The prevalence of smoking in Europe may have fallen since the 1960s, but young Europeans are smoking more than young Americans. Among young women smoking is probably increasing in most European countries.

Despite this Britain's new secretary of state for health is expected to line up with her opposite numbers in Germany, the Netherlands, and Greece to vote against the ban, thereby scuppering it. Apparently Mrs Bottomley believes that matters should be left to individual countries to decide. Her government favours voluntary controls, whose intentions advertisers can circumvent. Yet The Health of the Nation, which Mrs Bottomley will be trying to get through the cabinet soon, singles out rigarette smoking as the largest single preventable cause of death. ${ }^{3}$ Hers is, to say the least, a curious position to maintain.

Less curiously, the tobacco industry has thrown its weight against the ban. It claims that such a ban would unjustifiably curtail commercial freedom. If selling a product is legal, it asserts, then advertising it should not be made illegal. Both these propositions are based on shakier foundations than the government is currently willing to concede.

Supporters of the status quo argue that cigarette advertising simply enables manufacturers to compete effectively for bigger market shares for their brands. As the prevalence of smoking is falling slowly in the United Kingdom they argue that advertising cannot be blamed for the catalogue of death and disease that follows in smoking's wake.

But there is more to it than that. Five out of six adult smokers began smoking by the age of $16^{4}$-at a time when people are poorly equipped to judge its health risks and to resist its alluring image. Within a few years three out of four smokers are trying to give up but failing. ${ }^{5}$ No wonder: according to the United States Surgeon General giving up tobacco is as hard as giving up heroin. ${ }^{6}$ If advertising starts children on the road to addiction then a strong case exists for banning it.

How strong is the evidence? Studies suggest that, whatever tobacco companies' intentions and the current voluntary advertising restrictions, children are exposed to and notice cigarette advertisements. Posters and magazine advertisements are everywhere and visible to all. A recent Scottish survey of 11 to 14 year olds found that they could recognise on average five cigarette advertisements. ${ }^{7}$ Indeed, more than half this age group claim to have seen advertisements for cigarettes on television, which reflects the exposure given to sports events sponsored by tobacco companies. ${ }^{8}$

Children are influenced by cigarette advertising. Studies show that those who pay attention to cigarette advertisements are likely to change their views in favour of smoking ${ }^{79}$; ; those who approve of the advertisements are twice as likely to become smokers. Children who smoke more readily recall, recognise, and identify cigarette advertisements. Advertising therefore seems likely to encourage them to continue the habit. The most compelling evidence comes from a recent survey that showed that the four most heavily advertised cigarette brands-Benson and Hedges, Silk Cut, Embassy, and Marlboro-are the brands most smoked by 11 to 14 year olds. $^{8}$

Undoubtedly, stronger influences than advertising encourage children to take up or continue smoking. These include smoking by other family members and peer pressure. Nevertheless, a recent study for the Department of Health concluded that "There is some support for the view that tobacco advertising promotes smoking among young people." 11

Showing that advertising is one of the influences encouraging young people to take up smoking is not evidence that its absence would have the opposite effect. Examining the effect of advertising bans in other countries may help us here. This has been done by the Department of Health's economic advisers, who recently concluded that evidence from New Zealand and elsewhere showed that advertising bans led to significant falls in consumption. ${ }^{12}$ Particularly relevant is the change in the prevalence of smoking in young Norwegians. Among 13 to 15 year olds it fell from $17 \%$ in 1975 , when a ban on advertising was imposed, to $10 \%$ in $1990 .{ }^{13}$

Studies therefore strongly suggest that cigarette advertising and sponsorship are reaching and influencing young people and that banning advertising would reduce the numbers taking up smoking. It is in this light that the tobacco industry's demands for commercial freedom should be considered. With freedom come responsibilities; increasing the numbers of people who will suffer the ravages of tobacco induced ill health and premature death is a responsibility that sits uncomfortably with claims for the freedom to advertise.

Furthermore, the argument that businesses should be free to advertise what they are free to sell is seriously flawed in the case of tobacco. It is illegal to sell tobacco to people under 16. 
Yet preventing this group from seeing and being influenced by advertising, which is theoretically directed at an adult audience, is impossible. In effect, a product that cannot legally be sold to a particular sector of the population is being advertised to it. On legal, moral, and health grounds the case for a ban therefore seems overwhelming.

If the British government votes against a ban next week, ignoring its advisers and temporarily forgetting the contents of The Health of the Nation, it will be doing so in the face of widespread opposition to cigarette advertising. Two thirds of British adults favour a ban. ${ }^{14}$ So do a similar proportion of children. ${ }^{8}$

Deputy Chairman,

ADRIAN VICKERS

Abbott Mead Vickers · BBDO Ltd,

191 Old Marylebone Road,

London NW1 5DW
1 European Bureau for Action on Smoking Prevention. Newusletter 13 1991:10.

2 Dorrell S. Parliamentary written answer. House of Commons Official Report (Hansard) $1991 \mathrm{Apr}$ 24;189: col 473. (No 94.)

3 Secretary of State for Health. The health of the nation. London: HMSO, 1991. (Cm 1523.)

4 Office of Population Censuses and Surveys. General household survey 1988. London: HMSO, 1990.

5 Marsh A, Matheson J. Smoking attitudes and behaviour. London: HMSO, 1983. 6 US Department of Health and Human Resources. Health consequences of smoking: nicotine addiction. Resources, 1988.

7 Aitken PP, Eadie DR. Reinforcing effects of cigarette advertising on under-age smoking. $B r \mathcal{F}$ Addict 1990;85:399-412.

8 Roberts JL. Beating the ban. London: Health Education Authority, 1990.

9 Alexander HM, Callcott R, Dobson AJ, Hardes GR, Lloyd DM, O'Connell DL, et al. Cigarette smoking and drug use in schoolchildren: IV-Factors associated with changes in smoking behaviour. Int $f$ Epidemiol 1983;12:59-66.

10 Cancer Research Campaign. From the billboard to the playground. London: Cancer Research Campaign, 1991.

11 Office of Population Censuses and Surveys. Why children stan smoking. London: HMSO, 1990

12 News, BBC Radio 4, 1992 Jan 10.

13 Bjartveit K. Fifteen years of comprehensive legislation: results and some conclusions. In: Proceedings of seventh world conference on tobacco and health: the global war. Perth: West Australian Health Department, 1990.

14 Jowell R. British social attitudes (eighth report). Aldershot: Dartmouth, 1991.

\section{Microalbuminuria}

\section{Worth screening for in early morning urine samples in diabetic, hypertensive, and elderly patients}

Microalbuminuria is defined as urinary excretion of albumin that is persistently increased above normal although below the sensitivity of conventional semiquantitative test strips. It reflects glomerular, or less commonly tubulointerstitial, dysfunction and is usually deemed present only after structural abnormalities and infection of the renal tract have been excluded. Semiquantitative test strips have recently been validated for detecting microalbuminuria, although currently they are expensive $\mathrm{e}^{12}$ and their role is uncertain.

The classification of microalbuminuria has been hampered by a lack of consensus on the best way of collecting urine and expressing albuminuria quantitatively ${ }^{2}$ considerable postural and diurnal variation in individual subjects, ${ }^{2}$ and a suggestion of ethnic differences in its prevalence. ${ }^{3-5}$

For timed overnight urine collections an albumin excretion rate greater than $20 \mu \mathrm{g} / \mathrm{min}$ is considered to be diagnostic of microalbuminuria. ${ }^{2}$ At an excretion rate of about $200 \mu \mathrm{g} / \mathrm{min}$ conventional semiquantitative strips give a positive result for albuminuria; this defines the upper limit for microalbuminuria. An early morning urine sample with an albumin: creatinine ratio greater than 3.0 reliably predicts an overnight excretion rate greater than $30 \mu \mathrm{g} / \mathrm{min}$, making it a useful screening method. ${ }^{2}$ This negates the need for precisely timed and conducted urine collections, which are necessary only to confirm positive screening values. The prevalence of microalbuminuria in the general population is $2.2 \%$ in white adults aged $20-65^{3}$ and $13-20 \%$ in those aged $60-74^{6}$ and in Mexican Americans aged $25-64 .{ }^{4}$ In diabetes the true prevalence is probably about $7-10 \%$. $^{\text {? }}$

Microalbuminuria greater than $20 \mu \mathrm{g} / \mathrm{min}$ independently predicts impending nephropathy and cardiovascular morbidity and death in patients with diabetes mellitus. ${ }^{89}$ It also predicts death from cardiovascular disease in elderly patients ${ }^{10}$ and perhaps also coronary and peripheral vascular disease in the general population. ${ }^{11}$ Two broad explanations have been proposed to account for this: microalbuminuria is associated with an excess of known and potential cardiovascular risk factors and is a marker of established cardiovascular disease.

Microalbuminuria is correlated with raised blood pressure, not only in people with diabetes ${ }^{212}$ but also in people with benign essential hypertension, ${ }^{13}$ the general and elderly populations, ${ }^{3410}$ and those with established cardiovascular disease $^{11}$ In diabetic patients and elderly patients it acts $\mathscr{\mathscr { C }}$ synergistically with blood pressure in predicting morbidity and death from cardiovascular disease. ${ }^{8-10}$

Microalbuminuria may also be a marker of dyslipoproteinaemia in diabetes. The most consistent abnormality is a reduction in concentrations of high density lipoprotein cholesterol and apolipoprotein A I. ${ }^{12}{ }^{15}$ Changes in the composition of triglyceride rich lipoproteins ${ }^{14}$ and increased $L p(a)$ lipoprotein concentrations ${ }^{15}$ have also been recorded. In nondiabetic subjects increases in serum triglyceride concentration and reductions in high density lipoprotein cholesterol concentration may accompany microalbuminuria. ${ }^{34}$ In both diabetic and non-diabetic subjects microalbuminuria and high serum triglyceride concentration and low high density lipoprotein cholesterol concentration may be characterised by insulin resistance, ${ }^{314}{ }^{16}$ which itself may have a role in cardiovascular disease. ${ }^{16}$

Significantly increased platelet aggregability and turnover and increases in other haemostatic variables with microalbuminuria have been reported in patients with insulin $\delta$ dependent diabetes mellitus ${ }^{12}{ }^{17}$; no clear differences have been recorded in patients with non-insulin dependent dia- $\frac{\text { ? }}{3}$ betes mellitus or in the general population. ${ }^{318}$ Similarly, the $N$ suggestion that microalbuminuria is a marker of widespread endothelial dysfunction is based mainly on reports of increased circulating endothelial constituents in insulin $N$ dependent diabetes mellitus, ${ }^{19}$ although an associated $\underset{\omega}{\mathcal{N}}$ increased transcapillary escape of protein has been noted in 0 both insulin dependent diabetes mellitus and essential hypertension. ${ }^{192}$ The hypothesis that microalbuminuria and generalised endothelial damage are due to genetic polymorphism in enzymes involved in the metabolism of glycosaminoglycan components of the extracellular matrix ${ }^{19}$ has yet to be substantiated and may apply only to diabetes.

Autonomic neuropathy, which is also associated with microalbuminuria, ${ }^{21}$ is a particularly poor prognostic marker for (often sudden) death from cardiovascular disease in diabetic patients. ${ }^{22}$ Its prevalence in non-diabetic subjects is not known. People with microalbuminuria have an increased prevalence of symptomatic and asymptomatic electrocardiographic evidence of coronary heart disease ${ }^{3411}$; microalbuminuria has been recorded in one fifth of people with coronary heart disease. ${ }^{11}$ 